\title{
(2) OPEN ACCESS \\ Determining the skills needed by frontline NHS staff to deliver quality improvement: findings from six case studies
}

\author{
David Wright (D) , ${ }^{1}$ John Gabbay, ${ }^{2,3}$ Andrée Le May ${ }^{1,3}$
}

- Additional supplemental material is published online only. To view, please visit the journal online (http://dx.doi. org/10.1136/bmjqs-2021013065).

${ }^{1}$ School of Health Sciences, University of Southampton, Southampton, UK

${ }^{2}$ Wessex Institute, University of Southampton, Southampton, UK ${ }^{3}$ NIHR East of England Applied Research Collaboration, University of Cambridge, Cambridge, UK

\section{Correspondence to} Dr David Wright, School of Health Sciences, University of Southampton, Southampton SO17 1BJ, UK;

D.Wright@soton.ac.uk

Received 17 January 2021 Accepted 11 August 2021

\section{Check for updates}

(c) Author(s) (or their employer(s)) 2021. Re-use permitted under CC BY-NC. No commercial re-use. See rights and permissions. Published by BMJ.

To cite: Wright $D$, Gabbay J, Le May A. BMJ Qual Saf Epub ahead of print: [please include Day Month Year].

doi:10.1136/

bmjqs-2021-013065

\begin{abstract}
Background Previous studies have detailed the technical, learning and soft skills healthcare staff deploy to deliver quality improvement (QI). However, research has mainly focused on management and leadership skills, overlooking the skills frontline staff use to improve care. Our research explored which skills mattered to frontline health practitioners delivering QI projects.

Study design We used a theory-driven approach, informed by communities of practice, knowledge-inpractice-in-context and positive deviance theory. We used case studies to examine skill use in three pseudonymised English hospital Trusts, selected on the basis of Care Quality Commission rating. Seventy-three senior staff orientation interviews led to the selection of two QI projects at each site. Snowball sampling obtained a maximally varied range of 87 staff with whom we held 122 semistructured interviews at different stages of QI delivery, analysed thematically.

Results Six overarching 'Socio-Organisational Functional and Facilitative Tasks' (SOFFTs) were deployed by frontline staff. Several of these had to be enacted to address challenges faced. The SOFFTs included: (1) adopting and promulgating the appropriate organisational environment; (2) managing the QI rollercoaster; (3) getting the problem right; (4) getting the right message to the right people; (5) enabling learning to occur; and (6) contextualising experience. Each task had its own inherent skills.

Conclusion Our case studies provide a nuanced understanding of the skills used by healthcare staff. While technical skills are important, the ability to judge when and how to use wider skills was paramount. The provision of QI training and fidelity to the improvement programme may be less of a priority than the deployment of SOFFT skills used to overcome barriers. QI projects will fail if such skills and resources are not accessed.
\end{abstract}

\section{INTRODUCTION}

It is increasingly acknowledged that quality improvement (QI) programmes often fail to deliver their anticipated benefits. ${ }^{12}$ Understanding the reasons for this is complicated as initiatives are diverse and are delivered in disparate health and social care settings. ${ }^{3}$ Indeed,
QI projects or techniques may falter if they are viewed as 'magic bullets' without sufficient adaptation to local context. ${ }^{14}$

Many models have been proposed to explicate the complex processes of QI delivery. Collectively, the research literature reveals QI to be multifactorial and multidimensional, with varied contextual, people and process-related factors impacting on design, delivery and outcome. ${ }^{5} 6$ External contextual factors include policy and regulatory environments, which can generate 'organisational turbulence' when they shift, or strengthen commitment when they align to local priorities. ${ }^{78}$ Internal organisational factors include work cultures, which inhibit QI if they are rigid, coercive or blaming, and support QI if they foster an open, learning, inclusive environment where vision, values and goals are freely shared and clearly communicated. ${ }^{8-11}$

People factors include the commitment of the chief executive officer (CEO), board members and senior managers to QI and the involvement of 'change champions'. Barriers include professional 'tribalism', resistance to change and managerially driven improvement. $^{78} 12-19$ QI projects are thus more likely to succeed where teams operate beyond professional/disciplinary boundaries, and are interdisciplinary, collaborative, responsive and consultative. ${ }^{79-27}$ Process factors influencing QI delivery are diverse; they include understanding the problem, designing the right solution, setting appropriate timelines, developing effective data collection and monitoring systems, and ensuring change is embedded in practice. $^{782528}$ 
Healthcare teams deploy a range of skills when delivering QI in the face of these factors. Gabbay et $a l$, in their study of two UK hospital trusts, identified three skill sets staff use to deliver QI: technical, soft and learning skills. ${ }^{4} 29$ Technical skills include Plan, Do, Study, Act (PDSA) and Lean methodologies (which are the most likely to be used in healthcare $^{30}$ ) and the use of data to demonstrate problems, measure performance and assess impact. ${ }^{11}$ Learning skills include fostering multidisciplinary, team-based learning that encourages motivation, experimentation and psychological safety. ${ }^{1626}$ Soft skills are diverse and include transformational leadership, clear and consistent communication and negotiation skills. ${ }^{18} 253132$

While an extensive literature exists on 'improvement science' and the enablers/barriers to QI in healthcare, less attention has been given to the wider skills needed by staff to deliver effective improvement projects. Furthermore, while research has begun to explore QI delivery by frontline staff, ${ }^{33} 34$ studies have tended to focus more on managerial or leadership skills and less on the skills and competencies used by frontline health professionals trying to improve care. This is significant given the substantial investment in QI programmes and the continual demand for improved practice. The aim of our study was to identify which skills mattered most to frontline health practitioners (ie, those directly interacting with patients and the public) delivering QI, when they were deployed and why they were important. While several staff were experienced in QI methods, they were not QI leaders within the hospitals. We explored what factors facilitated or impeded skill use and why, and how staff were able to overcome barriers and capitalise on the facilitators.

\section{METHODS}

\section{Design}

We used a theory-driven approach to inform our study design, drawing on three concepts:

- Communities of practice $(\mathrm{CoPs})^{35-41}$ - people often learn in informal groups with similar interests, ideals and activities, exchanging ideas, aiding problem solving, developing skills and establishing a sense of collective identity.

- Knowledge-in-practice-in-context (K-I-P-I-C)/'contextual adroitness ${ }^{42}{ }^{43}$ - theoretical knowledge is transformed into K-I-P-I-C through social learning processes that occur where people work together on complex problems to achieve common goals.

- Positive deviance ${ }^{44}$ - understanding how some groups operating with similar resources succeed while others fail.

These concepts informed our research questions, foci of data collection and analytical framework, exploring the context-specific processes of skill use.

We used a case-study approach informed by ethnographic methods to surface the complex processes by which skills are put into collective practice.
Ethnography has been widely used in QI research to understand how people experience and understand the environment in which they operate. ${ }^{45}$

Three National Health Service (NHS) hospitals in England managed by trusts ('NHS hospital Trusts') were selected by the research team to ensure maximum variation in Care Quality Commission (CQC) rating. The selected Trusts (referred to by pseudonyms throughout this paper) were:

- 'Premton': a Trust with two main district hospitals with a sizeable population. CQC rated: 'outstanding'.

- 'Middleswick': a metropolitan Trust deeply embedded in its community with university hospital status. CQC rated: 'requires improvement'.

- 'Upsworth': a single-hospital Trust, mainly serving an urban population. In CQC 'special measures'.

\section{Orientation and case study selection}

JG and ALM conducted 73 preliminary interviews with CEOs, board members, senior managers, clinicians, team leads, other senior staff, including one group interview with directors. The purpose of these interviews was to orientate the research team to the hospitals' QI structures, processes and culture (including QI capability-building activities), exploring the internal and external contexts and identifying potential QI initiatives. These preliminary orientation interviews included frontline staff leading projects that were considered for inclusion in the study, and led to the agreement to follow two QI projects from each site, selected using the following criteria:

- Multidisciplinary.

- Involving staff recently exposed to capability building.

- Involving cross-organisational clinical services.

- Of strategic/operational importance.

- Having clear endpoints and outcomes.

We selected six projects focusing on 'nurse-led discharge' (NLD) and 'handover at night' (HAN) at Premton; 'enhanced care' (EC) and 'postural blood pressure' (PBP) at Middleswick; and 'managing unprofessional behaviour' (MUB) and 'tissue viability' (TV) at Upsworth (see table 1).

\section{Participant selection}

We obtained a maximally varied range of staff involved with QI projects through purposive snowball sampling, starting with key staff members identified by senior Trust directors as leading QI projects. Relevant participants were confirmed by cross-referencing during the interviews. Response rates were good with the exception of HAN where most people declined to participate or failed to respond. Recruitment continued until data saturation was sufficiently reached. ${ }^{46}$ Multiple interviews were held at different stages of QI delivery from prior to/early project work to postcompletion of the project where feasible or appropriate. We interviewed 87 staff on one to four occasions, resulting in 
Table 1 Summary of selected case studies

\begin{abstract}
NLD: Premton
Nurse-led discharge (NLD) was a suite of QI activities designed to speed up discharge initially on two specialised surgical units, but later adopted in other surgical wards. Led by senior surgical nurses, supported by most surgeons, the aim was to produce documents and checklists suitable for each surgical environment so that patients could routinely be discharged home or to less high-dependency wards without waiting for a doctor to decide.
\end{abstract}

\section{EC: Middleswick}

Enhanced care (EC) grouped patients with special nursing needs into one or more bays of a ward, so avoiding 'specialing' with 1:1 care, which put great strain on stretched wards. A team of enthusiastic nurses, led by selected senior nurses, developed the scheme over many months before rolling it out to a rigorous timetable across all wards.

\section{MUB: Upsworth}

Managing unprofessional behaviour (MUB), based on a proven US scheme, was designed to allow trained colleagues ('peer messengers') to avert poor behaviour by having carefully designed 'cup of coffee' conversations with 'transgressors', making them aware of their behaviour without the need of HR department's disciplinary procedures, unless they 'reoffend'.

A senior, doctor-initiated, multidisciplinary team lead the innovation.

BP, blood pressure; HR, human resource; QI, quality improvement.

a total of 122 interviews conducted over a maximum period of 14 months (table 2).

\section{Method of approach and data collection following orientation and selection}

Staff were given a brief verbal explanation of the study and an information sheet and signed consent was obtained before the first interview. Where meetings were observed, attendees who had not previously given consent did so after receiving written information before the meeting.

We developed an interview guide, informed by our literature review, which identified factors likely to be important in QI skill deployment (online supplemental

\section{HAN: Premton}

Handover at night (HAN) attempted to build on the success of the Trust's upgrade of ward daytime shift changeovers. HAN aimed to hold, besides the separate specialty-based handovers, an additional cross-disciplinary meeting of key night staff to discuss potentially problematic patients across the hospital.

\section{PBP: Middleswick}

Postural blood pressure (PBP) measurement helps avoid patients falling in hospital. It requires nurses to select at-risk patients and measure their BP standing and lying, which audits had shown was not done satisfactorily. A multidisciplinary team, led by an experienced specialist nurse, developed a programme to raise awareness and train ward staff.

\section{TV: Upsworth}

Tissue viability (TV), especially the excessive incidence of pressure sores, was a serious problem being tackled by a small, understaffed team of specialist nurses. One strand of activity was to introduce a new TV assessment tool (the Waterlow scale) across all relevant hospital wards.

Table 2 Participant characteristics by case study

\begin{tabular}{|c|c|c|c|c|c|}
\hline \multicolumn{2}{|l|}{ Premton } & \multicolumn{2}{|l|}{ Middleswick } & \multicolumn{2}{|l|}{ Upsworth } \\
\hline HAN & NLD & $\mathrm{EC}$ & PBP & TV & MUB \\
\hline $\begin{array}{l}\text { QI lead matron } \times 3 \\
\text { QI lead junior doctor } \times 2 \\
2 \text { Senior management team } \\
\text { members } \\
2 \text { consultants } \\
\text { Organisation development } \\
\text { manager } \\
1 \text { meeting observation }\end{array}$ & $\begin{array}{l}\text { QI lead matron } \times 2 \\
\text { Senior management team } \\
\text { member } \\
\text { Matron } \times 2 \\
2 \text { matrons } \\
\text { Senior sister } \times 2 \\
\text { Sister/charge nurse } \times 2 \\
\text { Sister/charge nurse } \\
2 \text { ward managers } \times 2 \\
4 \text { staff nurses } \\
2 \text { advanced nurse } \\
\text { practitioners } \\
\text { Consultant surgeon }\end{array}$ & $\begin{array}{l}\text { QI lead nurse } \times 3 \\
\text { QI lead nurse } \times 3 \\
\text { QI manager } \times 3 \\
\text { Matron } \times 2 \\
6 \text { ward managers } \\
5 \text { staff nurses } \\
4 \text { healthcare assistants } \\
\text { Director of nursing }\end{array}$ & $\begin{array}{l}\text { QI lead nurse } \times 3 \\
\text { QI physiotherapist } \\
\text { Consultant lead } \\
2 \text { matrons } \\
\text { Senior nurse } \\
2 \text { ward managers } \\
2 \text { staff nurses } \\
3 \text { healthcare assistants }\end{array}$ & $\begin{array}{l}\text { QI manager } \times 3 \\
\text { QI lead } \times 4 \\
2 \text { specialist nurses } \\
\text { Patient safety manager } \\
\text { Director of nursing } \times 2 \\
\text { Training manager } \\
\text { Link nurse } \\
3 \text { ward managers } \\
4 \text { staff nurses } \\
\text { Matron } \\
2 \text { physiotherapists } \\
\text { Student nurse } \\
\text { Healthcare assistant }\end{array}$ & $\begin{array}{l}\text { Senior clinical } \\
\text { manager } \times 2 \\
\text { Medical administrator } \\
\times 2 \\
\text { HR manager } \times 2 \\
\text { Consultant } \times 4 \\
\text { Consultant } \times 2 \\
\text { Senior nurse manager } \\
\text { Senior nurse manager } \\
\times 2 \\
\text { Administrator } \times 2 \\
\text { Trainer/manager } \\
\text { Training manager } \times 3 \\
1 \text { meeting } \\
\text { observation }\end{array}$ \\
\hline Total: 10 (+1 meeting) & 23 & 27 & 15 & 26 & 21 (+1 meeting) \\
\hline
\end{tabular}

Key: 2 participants $=2$ individuals interviewed once; $\times 2=2$ interviews with one participant, etc.

EC, enhanced care; HAN, handover at night; HR, human resource; MUB, managing unprofessional behaviour; NLD, nurse-led discharge; PBP, postural blood pressure; QI, quality improvement; TV, tissue viability.

appendix 1). The guide was piloted through three initial interviews with QI project leads from two participating sites, with subsequent refinement. Interviews were guided conversations, enabling questions to be adapted to responses. Interview topics were iteratively amended as findings emerged from the study.

Interviews were recorded (but not transcribed) in two of the case studies to ensure accurate recall. Recording was not necessary or feasible in the other case studies, where two interviewers worked together, one writing extensive fieldnotes. Most interviews were face to face and were conducted out of earshot from colleagues, with a small number of telephone follow-up interviews with staff and email conversations for clarification. 
JG and ALM jointly conducted the interviews in two sites (Middleswick and Upsworth), while DW held the interviews in Premton. In addition to general observations of ward activity while conducting the fieldwork, JG and ALM observed an MUB project meeting which focused on the design and delivery of the QI activity. DW observed a hospital-at-night handover, in which the HAN model was enacted. Formal observations of meetings lasted up to an hour and fieldnotes focused on challenges/opportunities and skills deployed. We also collected relevant documents associated with each QI project. All three researchers are experienced qualitative health service researchers, independent of the case-study sites. Because most interviews took place within the hospital, often on the wards, the researchers were able to undertake concurrent informal observations of the organisational 'feel' of the environment. We mostly maintained a non-participatory involvement (ie, we observed events but did not make recommendations for change), but in one case study (MUB), provided feedback during the project.

\section{Data analysis}

We analysed interviews, observational fieldnotes and relevant documents thematically with analysis of interviews occurring through repeated listening of recordings or reviewing of notes, from which key themes and supporting evidence were extracted. Analyses were initially conducted independently and then collectively to discuss emerging themes, which afforded an opportunity for assessing the reliability of the analysis. Emerging themes were reviewed iteratively as fieldwork progressed and, at the end of data collection, the three researchers held a 2-day analytical workshop from which a framework was developed of the agreed themes. These themes structured our account of the skills, the tasks they were used for, and their interrelationships. ${ }^{47}$ We shared case-study reports with QI leads to assess accuracy, all of whom responded and approved the analysis. A draft report was sent to site representatives/project leads for comment at the end of the project: no alterations were requested.

\section{RESULTS}

The projects had variable success (see table 3 ).

Our thematic analysis of the data was focused on the skills and tasks that frontline staff deployed when working on the projects. We identified six main 'SocioOrganisational Functional and Facilitative Tasks' (SOFFTs) (table 4). The SOFFTs had subcomponents that, like the SOFFTs themselves, were both skills and tasks, in the same way that, for example, giving an injection is both a task and a skill that relies on many component tasks/skills (eg, dose checking, asepsis, drawing up, positioning, reassurance, monitoring for anaphylaxis, recording). It was therefore not possible to differentiate between the tasks and the skills used in achieving SOFFTs. The overarching SOFFTs and their subcomponents were further dependent on a wide range of other more elementary technical, learning and 'soft' (interpersonal/organisational) tasks/skills. Not every QI project required every SOFFT. Projects struggled when the frontline staff leading them lacked the necessary SOFFT skills or were otherwise impeded from carrying out the necessary SOFFTs.

\section{SOFFT I: adopting and promulgating the appropriate organisational environment}

The style and tone adopted by frontline staff fostered a conducive learning environment that aided (or not) successful delivery of QI projects. We delineated eight components, both cultural and structural, of this overarching task.

\section{Ensuring a blame-free, nurturing and open environment}

Having clear communications, based on respectful but critical dialogue, generated an honest, supportive and

Table 3 Summary of case study outcomes

\section{Nurse-led discharge (NLD): Premton}

The introduction of NLD was under no time pressure, and was developed and audited in an inclusive way that, while coordinated, varied according to each unit's needs. It was successfully implemented across the units and appeared to be firmly embedded.

\section{Enhanced care (EC): Middleswick \\ The principle and new paperwork were accepted but EC practice was patchy, muddled and challenging. This was exacerbated by mixed messages about the motives for change and staff shortages. When fieldwork ended, the scheme was being redesigned and relaunched alongside wider work on reducing falls.}

\section{Managing unprofessional behaviour (MUB): Upsworth}

The team leading the innovation had initial problems in designing and implementing MUB locally, taking several months to resolve their internal interdisciplinary differences and difficulties. When fieldwork ended, they were on the way to training a cadre of peer messengers and launching the scheme.
Handover at night (HAN): Premton

Everyone agreed HAN was a good idea in principle, but never agreed what the problem was they were trying to solve, nor was the QI leadership clarified, nor was the backing of key senior clinicians forthcoming. Attendance was poor and the project fizzled out, despite an audit showing that it might have been effective in reducing the number of emergency calls from the wards at night.

\section{Postural blood pressure (PBP): Middleswick}

PBP measurement struggled to become embedded, with differences between hospitals, but greatest success was on wards with enthusiastic ward managers. Audits of fall incidence were disappointing and a reconfigured team was reconsidering the problem at a wider level, encompassing PBP among other factors.

Tissue viability (TV): Upsworth

After auditing, preparation and attempts to train staff on all wards, a small, understaffed QI team launched the new scheme. The message did not percolate to all staff, however, and there was patchy and unsatisfactory practice change with considerable confusion about the new scheme. Following a rethink and the establishment of a fully staffed QI team, matters improved greatly. 
Table 4 Examples of the 'Socio-Organisational Functional and Facilitative Tasks' (SOFFTs) and their associated skills

\section{SOFFTs/SOFFT skills}

Adopting and promulgating the

appropriate organisational environment:

- Ensuring a blame-free, nurturing and open environment.

Enabling staff to have difficult conversations

Ensuring the QI team can use technical QI skills.

- Fostering a strong sense of ownership by staff.

- Encouraging and rewarding good suggestions.

- Inculcating dedication to high-quality care

- Securing the resources to do the job.

- Leading staff towards the achievement of improvement.

Managing the QI rollercoaster:

- Avoiding 'initiativitis'.

- Timing, coordination and momentum.

\section{Getting the problem right:}

- Understanding properly what is wrong and why.

- Codesigning QI work.

Example of successful deployment of SOFFT skill deploying SOFFT skill

Ensuring a blame-free, nurturing and open environment: Enabling staff to have difficult conversations: HAN, PBP, Middleswick

Premton

A PBP lead attributed the initial success of the project Divisions between professional groups undermined to mutual trust, support and respectful critical dialogue. the HAN project. One problem was 'siloed' She persuaded staff to change practice by, 'knowing the handover meetings, with staff across specialties staff personally... always being there... never pulling rank or talking down to the staff or making them feel silly... being supportive and encouraging... giving feedback on performance without making people feel guilty, capitalising on staff's desire to do a good job fo their patients' (Senior nurse, PBP lead). and departments meeting at different times with conflicting agendas. This was never reconciled, with coleads saying they needed greater confidence in dealing with apathy and resistance, especially with senior staff: 'The initiative... was more top down, which means that although I was trying to do the bottom up bit, it felt there was a wedge in the middle that was somehow not really totally engaged' (QI lead junior doctor, HAN).

Timing, coordination and momentum: TV, Upsworth

The TV team needed to be persistent, determined and able to turn untoward events into opportunities when it became evident their enforced attempt to introduce change too rapidly was failing. They focused instead on just two high-risk wards, refining the approach before rolling out the change gradually. After 6 months, outcome data were more positive and the team's morale, having been rock bottom, was restored enough to carry out a more effective roll-out.

\section{Codesigning QI work: NLD, Premton}

The core-competency document underpinning much of the project was designed through: (1) collating clinical experience and information from the successful use of patient discharge elsewhere; (2) 'brainstorming' with senior staff, particularly senior sisters and matrons; (3) reviewing effective models of supported discharge from other Trusts. Such was the level of experience within the Trust and the level of acceptance, the competency document was successfully adopted without piloting.

Getting the right message to the right people:

- Getting the message right.

- Getting to the right people.

- Communicating.

\section{Getting the message right: NLD, Premton}

The nurses involved were aware that some consultant surgeons were dubious about the concept. They 'read' those consultants with skill, adapting their style to suit each individual. A ward manager, recognising that a head-on discussion might prove counterproductive, deliberately and slowly began using the nurse-led discharge terminology on every ward round until it became second nature for staff-resistant consultants included.

\section{Growing skills: PBP, Middleswick \\ Trowing skills. PBP, Middleswick}

Enabling learning to occur:

- Creating the necessary culture of learning.

Growing skills. at developing their intervention. The team felt the most valuable part of the course was meeting others doing similar work, learning from others' experience of problem solving. Formal presentations and posters were less helpful as they 'never really reported what they'd actually done' (Senior physiotherapist, PBP). It was helpful for the team to realise they were not behind everyone else in preventing falls, which boosted confidence.

\section{Avoiding 'initiativitis': EC, Middleswick}

There were concerns that changes to EC would be lost among so many other QI projects in the Trust. A lack of time meant EC was not properly established, a problem compounded by too many competing demands (eg, winter pressures) and too many ongoing improvement projects: 'They're all good projects but you can only do so much' (QI lead matron, EC). The result was that staff reverted to a culture that was less receptive to change.

\section{Understanding properly what is wrong and why:}

\section{HAN, Premton}

A key factor undermining this project was the failure to establish the problem they wanted to solve: 'It was very much process driven. It was, "We want to have a handover that looks like this" rather than, "the aim of changing our handover is..." Is it to make our patients safer? Is it to make our staff feel safer?...' (QI lead matron, HAN). In addition, there was no clarity on how and why handover was a problem, and so there was no agreement on the need for change.

Getting to the right people: EC, Middleswick The team relied on 'spreading the word' through informal networks across all ward managers. Some felt this strategy of letting the word travel from the initial wards created anticipation from other wards. In retrospect, though, most recognised a launch event would have been better: attending a meeting and having 'just a 10-minute slot to talk about it' did not have sufficient impact. Roll-out depended on staff relaying the message correctly, which was not guaranteed and resulted in distortion of the message.

\section{Creating the necessary culture of learning: TV} Upsworth

The TV QI lead attended a course on Lean methodology, which she found useless and of little relevance to clinical practice. Instead, she drew on her own expertise and the skills of others in delivering the TV project. Although initially disappointed, the TV frontline lead was retrospectively relieved not to be allowed to attend the course as she felt this would ultimately be a waste of her overstretched time. 
Table 4 Continued

\section{SOFFTs/SOFFT skills}

Contextualising experience:

- Adapting prior experiential learning.

- Using experience to modify the intervention.

- Transforming the original improvement to match the context.

Example of successful deployment of SOFFT skill deploying SOFFT skill

Transforming the improvement to match the context: $N L D$, Premton

The NLD project successfully balanced the need for fidelity to the improvement with adapting its design for different units. The matrons recognised that the diverse traditions of practice across wards required crucial adaptions without which it would have been rejected. They worked with staff to adapt NLD in a complex, diverse model, ensuring discharge activities were appropriate to the history and experience of each unit or ward.
Example of problems caused by not

Using experience to modify the intervention: $E C$, Middleswick

The EC project used an adapted PDSA approach, making small tests of change, considering lessons learnt, tweaking the intervention and trying again. However, EC failed to continue with PDSA once rollout had started, preventing methods from evolving to meet the contexts of wards not part of the initial development and piloting. Despite the varied reception and implementation between wards, the team felt compelled to stick to their strict timetable for spreading the practice, resulting in emerging problems not being addressed.

EC, enhanced care; HAN, handover at night; NLD, nurse-led discharge; PBP, postural blood pressure; QI, quality improvement; TV, tissue viability.

collaborative environment and a shared commitment to the QI activity. An open, shared understanding was necessary, 'respecting and working with your immediate subordinates so they feel they can contribute to your passion for this matter' (Ward manager, PBP) and with those working alongside and above the QI leads. Failing to create this environment caused problems in three case studies (MUB, TV, HAN).

\section{Enabling staff to have difficult conversations}

Staff were effective in changing practice when they questioned suboptimal processes (without punitive action) and persuaded others to change. This required managing and removing interpersonal/interprofessional tensions and boundaries. For example, when the MUB project was at risk of failing, the clinical leads intervened and decided to quietly chat 'offline' with their opponents on the project steering group. They demonstrated they understood their concerns, which enabled them to skilfully agree on a way forward.

\section{Ensuring the QI team can use technical QI skills}

Successful projects involved that task/skill of supporting staff to deploy appropriate technical skills. For example, a lack of benchmarking or initial audit data weakened the incentive for change, whereas enabling the staff to understand and harness data could help establish the need for change. NLD, for example, used audit data to demonstrate to initially resistant staff that fewer patients telephoned for help following discharge when the proposed documentation was used.

\section{Fostering a strong sense of ownership by staff}

It was important that staff had a shared view on the improvement required. For example, ward staff involved in PBP criticised the project for failing to 'have a working party that included people who actually take the blood pressures' (Ward manager, PBP). Engagement necessitated time, resources and socio-organisational intelligence regarding the timing of QI activity, but paid off in other projects.

Encouraging and rewarding good suggestions

Staff were more motivated to engage with a QI project if they felt genuinely involved, with a clear understanding of the resulting benefits. As one of the NLD team put it, projects succeed, 'if your staff feel they are being listened to and you are prepared to try something' (Senior sister, NLD). This required sufficient time to involve staff and to secure senior executive support for 'home grown' improvements.

Inculcating dedication to high-quality care

Instilling high professional values, emphasising the highest care standards and inspiring/admonishing where standards slip were important tasks/skills. For the EC and PBP projects, ward meetings, handovers and safety huddles helped to reinforce excellent care: 'It's all about the principles of good nursing; nothing more, nothing less' (Ward manager, PBP). Role modelling inculcated a desire to improve: 'If my staff can see me doing it, they are going to do it' (QI lead matron, NLD). This was more successful when tasks were led by clinically active staff rather than those imposing change remotely.

Securing the resources to do the job

Being responsive and matching the demands on the QI team to the resources required/available was an important organisational task/skill. Inadequate staffing undermined several case studies. Basic administrative support was important, particularly the provision of daily ward-based administration. The use of the Waterlow assessment scale for the TV project, for example, was hampered by ineffective nursing record administration (comprising 24 pages with 18 assessment sheets). 
Leading staff towards the achievement of improvement

The relationship between senior and frontline managers was important, ensuring the favourable environment espoused in the boardroom was embodied throughout the organisation. However, local standards of practice varied in each organisation, often due to frontline managers' management style. Effective leadership included enthusiasm, motivation, clear communication, setting clear direction and goals, conferring autonomy, providing resources, appointing the right team and helping them be creative and productive.

\section{SOFFT II: managing the QI rollercoaster}

Avoiding 'initiativitis'

The relentless demand for improvement led to staff feeling inundated by 'quality initiatives'. At Upsworth, the imperative to improve patient safety resulted in 'initiativitis', with numerous top-down improvements being implemented quickly and a perception that QI managers were making bureaucratic and uncomprehending demands. The tasks/skills required to survive 'initiativitis' included persistence and the ability to see unexpected events as opportunities. The TV team, for example, used the failed imposition of rapid change across the hospital as an opportunity to insist on getting it right in two wards before implementing elsewhere.

Timing, coordination and momentum

Time was needed to define the QI project, develop practice, assess progress and embed change. Tasks/ skills included ensuring adequate allocation of staff time and coordinated leadership, which involved QI leads delivering improvement within the context of other changes. 'Getting the timing right' was a frequently used skill, as exemplified in NLD, where leads 'read' wards, judging when to push and when to support, which also enhanced their credibility.

\section{SOFFT III: getting the problem right}

\section{Understanding properly what is wrong and why}

Several QI projects failed because the initial problem/ solution was not sufficiently determined. Direct clinical experience among QI leads helped them understand the full consequences of what staff were being asked to do. Most projects used literature, audits, experiences from other Trusts and talking to staff to develop the intervention. Only the NLD team were able to involve sufficient staff to implement a fully representative QI design. Conversely, HAN failed because neither the problem nor the solution was well defined: 'We started with the idea that this meeting would be a very good idea, but we weren't quite sure of what the problem was we were fixing' (QI lead junior doctor, HAN).

Codesigning QI work

Ensuring careful and appropriate consultation with involved parties was essential in understanding the problem and designing the best QI solution. Successful projects typically involved wide consultation in the initial stages, which enabled knowledge, data and experiences to be shared and potential challenges to be highlighted. For example, the PBP group was self-selected, which meant that the project faltered as the level of ignorance of blood pressure management was underestimated, a problem that could have been addressed early if senior ward nurses had been involved initially.

\section{SOFFT IV: getting the right message to the right people \\ Getting the message right}

The art of framing and 'selling' an improvement was important, requiring the identification of the right staff, understanding resistance/support for change and tailoring communication styles. For example, PBP persuaded nurses to engage by explaining that avoiding falls triggered by postural hypotension would benefit patients and reduce staff workload. The skill of framing had drawbacks, however: EC pitched the QI rationale differently to different staff (for ward managers, improving staffing ratios; for matrons, increasing patient safety; for managers, reducing costs). This was interpreted as 'mixed messaging' at best, and cynical spin at worst.

\section{Getting to the right people}

Getting the QI message to staff was important but challenging due to shift work, the pressure of clinical duties, under-resourcing and staffing problems. Four projects (PBP, TV, EC, HAN) were unable to achieve this. Approaches for communicating QI messages included ward meetings, 'trolley dashes', 1:1 coaching and onsite/sessional training, although most of these involved reaching the staff on duty and hoping information would trickle down to others. Often it did not; and if it did, it was usually distorted. Other skills involved building commitment, using appropriate methods to achieve change (eg, 'warm chats', not 'cold emails') and 'knowing the place' (eg, when and how to discuss QI).

\section{Communicating}

The tasks/skills needed to frame messages required fundamental personal skills and socio-organisational intelligence. Of these, communication was frequently cited, including the art of listening, engaging, being clear what was expected, explaining the need for change and the resultant benefit, anticipating needs and views and motivating others. One of the HAN leads admitted she had failed to communicate the project effectively to senior staff, which provided them an opportunity to instruct their teams not to participate. 


\section{SOFFT V: enabling learning to occur}

Creating the necessary culture of learning

Each Trust deployed different approaches to QI learning and development. Premton favoured an approach that implicitly put QI at the centre of learning and included coaching, mentoring, preceptorship, on-site training, road shows and 'skills blitzes'. This used homegrown online tools, educational videos and the inclusion of QI in staff inductions. A well-established and respected in-house action-learning programme on change management/ improvement skills enabled attendees to develop leadership and technical improvement skills (eg, PDSA) while working on their project. Conversely, the training department at Upsworth did not have QI at the heart of all their training, nor was it part of the induction process. QI training was provided through a set of specific, graded Lean-based courses run by the external consultancy using fictitious case studies. The course was not received well, with attendees finding content irrelevant, unhelpful and difficult to apply.

\section{Growing skills}

Interviewees typically were unable to identify where they attained the skills required to deliver QI. NLD leads reported that Premton's improvement-skills programme provided an understanding of staff behaviours, resistance and influencing strategies. The main benefit, however, was learning from 'counterparts in all the other areas, so you get to find out what other people's struggles are' (Senior sister, NLD). Technical QI skills training, such as PDSA, was hardly mentioned, while communication and influencing skills were often gained through professional experience. Gatherings, resembling spontaneous CoPs, provided opportunities for informal learning. For example, regular meetings with peers enabled ideas and experiences to be shared and helped senior nurses implementing NLD overcome difficulties. Mentoring was also valued for skills transfer, particularly mutual mentoring, although this risked perpetuating incorrect messages.

\section{SOFFT VI: contextualising experience}

\section{Adapting prior experiential learning}

Using prior experience appropriately and adaptively to suit new contexts-recognising that what worked in one environment may not translate to others-was an important skill. For example, HAN found to its cost that highly successful improvements to handover between the day nursing shifts did not translate to the night-time multidisciplinary handover meetings. Modifying previous experience sometimes required managing previous negative experiences. With HAN, 'it had been tried before in various different forms and at different times [unsuccessfully]..., so trying to get buy-in from the start was tricky' (QI lead junior doctor, HAN).
Using experience to modify the intervention

PDSA was almost the only formal QI technique used, being applied in four projects (EC, PBP, NLD, HAN). PDSA provides a systematic learning from experience through small tests of change, learning from what happened, tweaking the intervention and trying again. However, PDSA was occasionally misunderstood and misapplied. In the EC project, the approach was abandoned, which contributed to the project's failure as it prevented EC from evolving to suit the varied contexts of wards not involved in the pilot. Knowing when to stop and when to persist was particularly important: as a HAN lead reflected, 'Do we keep on doing it because somewhere on an action plan we said we had to do it, or do we decide that actually our priorities have changed?' (QI lead matron, HAN). In contrast, it was the team's dogged, flexible persistence against all odds that kept the TV project alive.

Transforming the original improvement to match the context

Matching an initiative to its context was an axiomatic task/skill, requiring contextual empathy to modify an intervention to be congruent with existing practice. The NLD leads were particularly adroit in adapting the QI design to different units while still adhering to the planned improvement. In contrast, the EC project faltered when the intervention was uniformly rolled out without adaptation to the different ward contexts. Finally, the MUB project faced fierce arguments about how far the US model (which did not translate well to the UK context) could be transformed without losing its essence. At a corporate level, there was also the need to ensure the local aims of the QI initiative could be met while still conforming to the demands of NHS policy.

\section{DISCUSSION}

Previous studies suggest that successful QI interventions require technical, soft and learning skills. ${ }^{49}$ Our case studies provide a deeper, nuanced understanding of the skill sets typified in each of these domains. Regarding technical skills, our findings confirm that PDSA and Lean approaches are commonly adopted, although often in a diluted form. ${ }^{30}$ However, while these technical skills are important, ${ }^{7}$ the ability to judge when and how to use them was paramount. NLD succeeded by adapting technical QI skills to suit the local context. This implies that when it comes to frontline staff, the provision of QI training may be less of a priority than the literature suggests. ${ }^{1} 84849$ What helps deliver successful QI projects is the ability to adapt skills and draw on other SOFFT skills to address barriers. Similarly, while the literature suggests that a good understanding of data is necessary for QI, 7811142650 our study found that this is not always important in the frontline. For example, the TV project only had a basic level of data collection and analysis, but this sufficed for their needs. The use of data thus 
depends on the nature of the QI intervention and, for frontline staff, a lack of statistical or research skills is not always a major concern.

With learning skills, previous studies have highlighted the need for multidisciplinary, team-based approaches to learning. ${ }^{16} 265152$ While relational skills of communicating, motivating and leading are recognised as important, they are often omitted in QI training, ${ }^{53}$ which may partly explain why interviewees were unable to articulate where they learnt them; they seemed to have developed cumulatively through daily interaction in healthcare. SOFFT skills were more likely to be developed through informal interactions, or spontaneous Communities of Practice, where knowledge, skills and ideas are shared, discussed and developed, which could impact on the success of the project. ${ }^{35-41}$

With regard to soft skills, research has shown these to be numerous and diverse. Effective leadership and creating psychologically safe and confidential environments to improve performance are important, ${ }^{16} 54$ as is ensuring change is achieved collegiately and not simply through managerially led directives. ${ }^{7245}$ Team skills that promote interdisciplinarity and an ability to transcend professional/disciplinary boundaries when solving problems are also important. ${ }^{485657}$ Our case studies confirm these findings, but again the lived reality for staff delivering QI was the need to adapt the deployment of these skills. The skills of knowing whom to involve, how, at what stage and to what degree are complex. There were occasions where a clear directive was required, while others needed a more consultative approach: the skill was judging which approaches were required. Half of the case studies were led by multidisciplinary teams, although there were times when tribalism remained, eroding the collegiality of the multidisciplinary feel, as with the HAN project.

Timing the interventions is an important SOFFT, particularly in contending with 'initiativitis/campaign fatigue'. ${ }^{58}{ }^{59}$ Our case studies demonstrated that this too required adaptivity. For NLD, this entailed giving the project all the time it needed (over 2 years) to bring about the cultural change sought. It also demonstrated the need to be flexible, responding to current situations, being sensitive to the staff's sense of being overwhelmed, the skill of knowing when to back off and when to push. Research has shown that effective, early and ongoing communication is important in ensuring staff are clear about the purpose of the QI initiative. ${ }^{116061}$ An important skill confirmed through our findings was the need to 'frame' communications to different individuals or situations. ${ }^{326263}$ Several of our case studies deployed framing, although for the EC project this caused problems of 'mixed messages'.

Viewed collectively, our case studies reveal that the structure of technical, learning and soft skill sets as set out by Gabbay et $a l^{4}$ was oversimplified. Each skill domain is mutually supporting, such that the application of technical skills often involved other softer skills, such as effective communication. ${ }^{32} 53$ Whether QI succeeded or foundered was down to whether frontline staff were able to adapt their skill sets, applying the right skill at the right time. This required 'contextual adroitness', situating theoretical/practical QI knowledge within clinical/organisational experience, enabling projects to be delivered in complex and shifting circumstances. ${ }^{42}$ Fidelity over design or proficiency in specific techniques, such as PDSA, was less of an issue than is sometimes reported. ${ }^{184849}$ It was more important to know when a QI technique was good enough and to have a varied arsenal of skills.

\section{Implications}

Our study reveals that QI projects can flounder if skills and resources for SOFFTs are not supported. Therefore, we recommend that a rapid audit be undertaken to assess readiness for improvement prior to attempting QI. To that end, we have developed a Fitness For Improvement Tool (https://www.health. org.uk/sites/default/files/2021-07/the_fitness_for_ improvement_tool.pdf) to be included in publishe $\bar{d}$ version) based on our above analysis. It is designed to help staff judge their capacity for undertaking the necessary SOFFTs before embarking on an improvement programme. This tool is yet to undergo formal validation, but is intended to be used, perhaps alongside other more formal tools that support related activity, ${ }^{6465}$ as an aid to assessing where resources and skills need to be strengthened before undertaking a QI project. Our findings underscore the importance of creating and resourcing opportunities for managers, QI leads and frontline staff to think, talk and debate openly together, using respectful critical dialogue, if improvement skills are to be used to deliver change effectively.

\section{Limitations}

There were limitations that should be noted regarding the execution of this study. First, given the complex environment in which QI activities were delivered, it was not possible to follow all projects over the whole course of their delivery. As the longest time frame over which a project was followed was 14 months, it was not feasible to capture the early genesis for some projects, or for others to assess the impact of the QI. Second, the situation on the ground limited the opportunity for observation during the case studies, which compromised, for example, the opportunity to track the role of informal learning and skills exchange in CoPs. Third, while interviewee recruitment was good in five of the case studies, it was notable that the response rate was poor in the sixth, least successful, project (HAN), although the open discussion encouraged by the confidential nature of the interviews and the range of people recruited (supporters and critics) minimised the impact on data analysis. 


\section{CONCLUSION}

These six case studies in three Trusts confirmed that improvement relies on technical, learning and soft skills. ${ }^{4}$ However, they also highlighted that fidelity of QI technical skills is not as important as adapting all three skill types to suit local contexts and, in particular, using soft skills to exploit strengths and opportunities, and overcome weaknesses and obstacles where these occur. This highlights the importance of the oftenunderplayed relational work of QI. QI occurred largely through the sensitive and contextualised deployment of interlinked SOFFTs and skills at the frontline.

Acknowledgements We would like to acknowledge all the staff at the three participating Trusts who generously gave their time to share their experiences of delivering the QI projects. We particularly would like to thank the QI leads who gave permission to follow their projects and interview them on multiple occasions.

Contributors JG, ALM and DW contributed to design of the study, recruitment, data collection, analysis and the drafting of all iterations of this paper.

Funding This report presents independent research funded by the Health Foundation (award number 1273806).

Competing interests None declared.

Patient consent for publication Not required.

Ethics approval The project received ethical approval and was registered with HRA (IRAS reference 216254) and with the University of Southampton (ERGO reference 23844). All findings were pseudonymised, including Trust and participant names, and identifying details were removed.

Provenance and peer review Not commissioned; externally peer reviewed.

Data availability statement Due to the nature of qualitative data and assured confidentiality to participants, no data are available.

Supplemental material This content has been supplied by the author(s). It has not been vetted by BMJ Publishing Group Limited (BMJ) and may not have been peer-reviewed. Any opinions or recommendations discussed are solely those of the author(s) and are not endorsed by BMJ. BMJ disclaims all liability and responsibility arising from any reliance placed on the content. Where the content includes any translated material, BMJ does not warrant the accuracy and reliability of the translations (including but not limited to local regulations, clinical guidelines, terminology, drug names and drug dosages), and is not responsible for any error and/or omissions arising from translation and adaptation or otherwise.

Open access This is an open access article distributed in accordance with the Creative Commons Attribution Non Commercial (CC BY-NC 4.0) license, which permits others to distribute, remix, adapt, build upon this work noncommercially, and license their derivative works on different terms, provided the original work is properly cited, appropriate credit is given, any changes made indicated, and the use is noncommercial. See: http://creativecommons.org/licenses/by-nc/4. $0 /$.

\section{ORCID iD}

David Wright http://orcid.org/0000-0003-4857-5084

\section{REFERENCES}

1 Dixon-Woods M, Martin GP. Does quality improvement improve quality? Future Hosp J 2016;3:191-4.

2 Moraros J, Lemstra M, Nwankwo C. Lean interventions in healthcare: do they actually work? A systematic literature review. Int J Qual Health Care 2016;28:150-65.
3 Alexander JA, Hearld LR. What can we learn from quality improvement research? A critical review of research methods. Med Care Res Rev 2009;66:235-71.

4 Gabbay J, le May A, Connell C, et al. Skilled for improvement? learning communities and the skills needed to improve care: an evaluation service development. The health Foundation, 2014. Available: https://www.health.org.uk/publication/skilledimprovement [Accessed 15 Jan 2021].

5 Nickel NC, Taylor EC, Labbok MH, et al. Applying organisation theory to understand barriers and facilitators to the implementation of baby-friendly: a multisite qualitative study. Midwifery 2013;29:956-64.

6 Pettigrew AM, Whipp R. Managing change for competitive success. Blackwell Publishers: Oxford, 1993.

7 Dixon-Woods M, McNicol S, Martin G. Ten challenges in improving quality in healthcare: lessons from the Health Foundation's programme evaluations and relevant literature. BMJ Qual Saf 2012;21:876-84.

8 Zayas LE, McMillen JC, Lee MY, et al. Challenges to quality assurance and improvement efforts in behavioral health organizations: a qualitative assessment. Adm Policy Ment Health 2013;40:190-8.

9 Crema M, Verbano C. Guidelines for overcoming hospital managerial challenges: a systematic literature review. Ther Clin Risk Manag 2013;9:427-41.

10 Eldh AC, Fredriksson M, Halford C, et al. Facilitators and barriers to applying a national quality registry for quality improvement in stroke care. BMC Health Serv Res 2014;14:354.

11 Aveling E-L, Martin G, Armstrong N, et al. Quality improvement through clinical communities: eight lessons for practice. J Health Organ Manag 2012;26:158-74.

12 Cheyne H, Abhyankar P, McCourt C. Empowering change: realist evaluation of a Scottish Government programme to support normal birth. Midwifery 2013;29:1110-21.

13 Liddy CE, Blazhko V, Dingwall M, et al. Primary care quality improvement from a practice facilitator's perspective. $B M C$ Fam Pract 2014;15.

14 Leemans K, Van den Block L, Vander Stichele R, et al. How to implement quality indicators successfully in palliative care services: perceptions of team members about facilitators of and barriers to implementation. Support Care Cancer 2015;23:3503-11.

15 Matthaeus-Kraemer CT, Thomas-Rueddel DO, Schwarzkopf $\mathrm{D}$, et al. Barriers and supportive conditions to improve quality of care for critically ill patients: a team approach to quality improvement. J Crit Care 2015;30:685-91.

16 Bergs J, Lambrechts F, Simons P, et al. Barriers and facilitators related to the implementation of surgical safety checklists: a systematic review of the qualitative evidence. BMJ Qual Saf 2015;24:776-86.

17 Marmor GO, Li MY. Improving emergency department medical clinical handover: barriers at the bedside. Emerg Med Australas 2017;29:297-302.

18 Flynn R, Rotter T, Hartfield D, et al. A realist evaluation to identify contexts and mechanisms that enabled and hindered implementation and had an effect on sustainability of a lean intervention in pediatric healthcare. BMC Health Serv Res 2019;19:912.

19 Leyenaar JK, Andrews CB, Tyksinski ER, et al. Facilitators of interdepartmental quality improvement: a mixedmethods analysis of a collaborative to improve pediatric community-acquired pneumonia management. BMJ Qual Saf $2019 ; 28: 215-22$. 
20 Lachman P, Runnacles J, Dudley J, et al. Equipped: overcoming barriers to change to improve quality of care (theories of change). Arch Dis Child Educ Pract Ed 2015;100:13-18.

21 Goeschel CA, Wachter RM, Pronovost PJ. Responsibility for quality improvement and patient safety: Hospital board and medical staff leadership challenges. Chest 2010;138:171-8.

22 Bohmer RMJ, Bloom JD, Mort EA, et al. Restructuring within an academic health center to support quality and safety: the development of the Center for Quality and Safety at the Massachusetts General Hospital. Acad Med 2009;84:1663-71.

23 Scholefield $\mathrm{H}$. Embedding quality improvement and patient safety at Liverpool Women's NHS Foundation Trust. Best Practice and Research in Clinical Obstetrics and Gynaecology 2007;21:593-607.

24 Herepath A, Kitchener M, Waring J. A realist analysis of hospital patient safety in Wales: applied learning for alternative contexts from a multisite case study. Health Services and Delivery Research 2015;3:1-242.

25 Green SA, Bell D, Mays N. Identification of factors that support successful implementation of care bundles in the acute medical setting: a qualitative study. BMC Health Serv Res 2017;17:120.

26 Gotlib Conn L, McKenzie M, Pearsall EA, et al. Successful implementation of an enhanced recovery after surgery programme for elective colorectal surgery: a process evaluation of champions' experiences. Implement Sci 2015;10:99.

27 Lamming L, McDonach E, Mohammed MA, et al. Barriers and enablers to the implementation of a complex quality improvement intervention for acute kidney injury: a qualitative evaluation of stakeholder perceptions of the Tackling AKI study. PLoS One 2019;14:9.

28 Shah V, Warre R, Lee SK. Quality improvement initiatives in neonatal intensive care unit networks: achievements and challenges. Acad Pediatr 2013;13:S75-83.

29 Gabbay J, le May A, Connell C, et al. Balancing the skills: the need for an improvement pyramid. BMJ Qual Saf 2018;27:85-9.

30 Zoutman DE, Ford BD. Quality improvement in hospitals: barriers and facilitators. Int J Health Care Qual Assur 2017;30:16-24.

31 Masood M, Afsar B. Transformational leadership and innovative work behavior among nursing staff. Nurs Inq 2017;24:4.

32 Millar R. Framing quality improvement tools and techniques in healthcare the case of improvement leaders' guides. J Health Organ Manag 2013;27:209-24.

33 Ginsburg L, Easterbrook A, Berta W, et al. Implementing Frontline Worker-Led Quality Improvement in Nursing Homes: Getting to "How". Jt Comm J Qual Patient Saf 2018;44:526-35.

34 Montgomery C, Parkin S, Chisholm A, et al. 'Team capital' in quality improvement teams: findings from an ethnographic study of front-line quality improvement in the NHS. BMJ Open Qual 2020;9:e000948.

35 Brown JS, Duguid P. Organizational learning and Communities-of-Practice: toward a unified view of working, learning, and innovation. Organization Science 1991;2:40-57.

36 Lave J, Wenger E. Situated learning: legitimate peripheral participation. Cambridge: Cambridge University Press, 1991.

37 Wenger E. Communities of practice: learning, meaning and identity. Cambridge: Cambridge University Press, 1998.
38 Wenger E, McDermott R, Snyder WM. Cultivating communities of practice. Boston: Harvard Business School Press, 2002.

39 Gabbay J, le May A, Jefferson H, et al. A Case Study of Knowledge Management in Multiagency Consumer-Informed consumer-informed 'Communities of Practice': Implications for Evidence-Based Policy Development in Health and Social Services. Health 2003;7:283-310.

40 le May A. Communities of practice in health and social care. Oxford: Wiley-Blackwell, 2009.

41 Wenger-Trayner E, Fenton-O'Creevy M, Kubiak C, eds. Learning in Landscapes of Practice: Boundaries, identity, and knowledgeability in practice-based learning. Abingdon: Routledge, 2014.

42 Gabbay J, le May A. Practice-Based evidence for healthcare: clinical mindlines. London: Routledge, 2011.

43 Gabbay J, le May A. Mindlines: making sense of evidence in practice. Br J Gen Pract 2016;66:402-3.

44 Lawton R, Taylor N, Clay-Williams R, et al. Positive deviance: a different approach to achieving patient safety. BMJ Qual Saf 2014;23:880-3.

45 Leslie M, Paradis E, Gropper MA, et al. Applying ethnography to the study of context in healthcare quality and safety. BMJ Qual Saf 2014;23:99-105.

46 Corbin J, Strauss A. Strategies for qualitative data analysis. In: Basics of qualitative research. $3 \mathrm{rd}$ ed. Los Angeles, London: Sage, 2008: 65-86.

47 Reeves S, Kuper A, Hodges BD. Qualitative research methodologies: ethnography. BMJ 2008;337:a1020.

48 Davis KF, Napolitano N, Li S, et al. Promoters and barriers to implementation of tracheal intubation airway safety bundle: a mixed-method analysis. Pediatr Crit Care Med 2017;18:965-72.

49 Pronovost PJ, Miller MR, Wachter RM, et al. Perspective: Physician leadership in quality. Acad Med 2009;84:1651-6.

50 van Sluisveld N, Oerlemans A, Westert G, et al. Barriers and facilitators to improve safety and efficiency of the ICU discharge process: a mixed methods study. BMC Health Serv Res 2017;17:251.

51 Forsner T, Hansson J, Brommels M, et al. Implementing clinical guidelines in psychiatry: a qualitative study of perceived facilitators and barriers. BMC Psychiatry 2010;10:8.

52 Tucker AL, Nembhard IM, Edmondson AC. Implementing new practices: an empirical study of organizational learning in hospital intensive care units. Manage Sci 2007;53:894-907.

53 Baker NJ, Suchman A, Rawlins D. Hidden in plain view: barriers to quality improvement. Physician Leadersh J 2016;3:54-7.

54 Vakani FS, O'Beirne R. Performance improvement CME for quality: challenges inherent to the process. Int J Health Care Qual Assur 2015;28:746-50.

55 New S, Hadi M, Pickering S, et al. Lean participative process improvement: outcomes and obstacles in trauma orthopaedics. PLoS One 2016;11:e0152360.

56 Santana C, Curry LA, Nembhard IM, et al. Behaviors of successful interdisciplinary hospital quality improvement teams. J Hosp Med 2011;6:501-6.

57 Amalberti R, Auroy Y, Berwick D, et al. Five system barriers to achieving ultrasafe health care. Ann Intern Med 2005;142:756-64.

58 Ozieranski P, Robins V, Minion J, et al. Running a hospital patient safety campaign: a qualitative study. J Health Organ Manag 2014;28:562-75. 


\section{Original research}

59 Stefancyk A, Hancock B, Meadows MT. The nurse manager: change agent, change coach? Nurs Adm $Q$ 2013;37:13-17.

60 Ijkema R, Langelaan M, van de Steeg L, et al. What impedes and what facilitates a quality improvement project for older hospitalized patients? Int J Qual Health Care 2014;26:41-8.

61 Parand A, Benn J, Burnett S, et al. Strategies for sustaining a quality improvement collaborative and its patient safety gains. Int J Qual Health Care 2012;24:380-90.

62 Armstrong N, Herbert G, Brewster L. Contextual barriers to implementation in primary care: an ethnographic study of a programme to improve chronic kidney disease care. Fam Pract 2016;33:426-31.
63 Nigam A, Huising R, Golden BR. Improving Hospital efficiency: a process model of organizational change commitments. Med Care Res Rev 2014;71:21-42.

64 Helfrich CD, Li Y-F, Sharp ND, et al. Organizational readiness to change assessment (ORCA): Development of an instrument based on the Promoting Action on Research in Health Services (PARIHS) framework. Implement Sci 2009;4:38.

65 Dana B: continuous quality improvement (CQI) readiness assessment and process tool 2004 AHCA/ NCAL. Available: https://www.ahcancal.org/ncal/quality/documents/cqi_rai_tool. pdf [Accessed 15 Jan 2021]. 